\title{
DAS MARGENS PARA O ECRÃ: MULHERES NA FICÇÃO CINEMATOGRÁFICA MOÇAMBICANA ${ }^{1}$
}

\section{Resumo}

A singularidade da história do cinema feito em Moçambique depois da independência do país faz com que o cinema moçambicano seja alvo, nos últimos anos, de forte interesse da academia a nível internacional. São, no entanto, ainda muito raros, ou mesmo inexistentes, estudos específicos sob a perspetiva de género no cinema moçambicano. O presente artigo é uma aproximação intersecional a dois (2) filmes moçambicanos contemporâneos: relacionam-se aspetos de género, raça e classe, numa análise de caráter crítico discursivo, para perceber a forma como são representadas as mulheres no cinema moçambicano dos nossos dias e como essas representações propõem, ou não, olhares alternativos às representações hegemónicas da mulher na sociedade moçambicana.

Palavras-chave: Cinema Moçambicano, Intersecionalidade, Sol de Carvalho, Licínio Azevedo

\section{Abstract}

From the margins to the screen: women in Mozambican film fiction

The singularity of the history of cinema made in Mozambique after the independence of the country has made the Mozambican cinema in recent years a target of international interest in the academy. However, there are still very few, if any, specific studies on gender in Mozambican cinema. This article is an intersectional approximation to two (2) contemporary Mozambican films: gender, race and class aspects are related in a critical discursive analysis to understand the way women are represented in today's Mozambican cinema, and how these representations propose, or not, alternatives to the hegemonic representations of women in Mozambican society.

Keywords: Mozambican Cinema, Intersectionality, Sol de Carvalho, Licínio Azevedo

\section{Resumen}

De los márgenes para la pantalla: las mujeres de Mozambique en el cine de ficción

La singularidad de la historia del cine realizado en Mozambique después de la independencia del país hace con que las películas de Mozambique tengan asumido gran interés de la academia internacional en los últimos años. Sin embargo, en el cine de Mozambique, los estudios específicos sobre el género son muy poco frecuentes o incluso inexistentes. Este

Centro de Estudos de Comunicação e Sociedade, Instituto de Ciências Sociais da Universidade do Minho (CECS/UM), Portugal.

Endereço eletrónico: ana.c.pereira@outlook.com

Endereço postal: Campus de Gualtar, 4710-057 Braga, Portugal.

1 Este artigo faz parte de uma investigação de doutoramento em estudos culturais, financiada pela Fundação para a Ciência e a Tecnologia, no domínio das Ciências da Comunicação, com a referência SFRH/BD/110044/2015. 
artículo presenta un enfoque interseccional de dos películas contemporáneas de Mozambique: se relacionan aspectos de género, raza y clase, en una análisis de carácter discursivo, para entender cómo se representan las mujeres en el cine de Mozambique en los días de hoy y cómo estas representaciones proponen, o no, enfoques alternativos a las representaciones hegemónicas de las mujeres en la sociedad de Mozambique.

Palabras-clave: Cine mozambiqueño, Interseccionalidad, Sol de Carvalho, Licínio Azevedo

\section{Introdução}

A presente reflexão procura perceber de que forma aspetos de género, raça e classe se relacionam e potenciam, nos processos de produção e nas representações de opressão, no cinema ficcional feito em Moçambique. Ainda na introdução esclarecem-se algumas premissas da teoria intersecional e do trabalho. Num segundo momento, é traçada uma breve historiografia do cinema moçambicano até à atualidade, para contextualizar as longas-metragens de ficção que são analisadas posteriormente. Os dois filmes analisados são O Jardim do Outro Homem, de Sol de Carvalho (2006), e Virgem Margarida, de Licínio Azevedo (2012). A análise consiste essencialmente num diálogo crítico com as representações das mulheres propostas pelas obras.

\section{Uma aproximação intersecional}

A abordagem intersecional nasce na década de 1970 no contexto do movimento feminista negro e das lutas antirracistas. bell hooks (1990 [1982]; 2000) acusa o feminismo liberal/reformista de pensar as mulheres como um grupo homogéneo (brancas, classe média, heterossexuais), não permitindo compreender as formas como o género, classe, raça e religião se combinam para determinar os percursos de vida de mulheres com diferentes categorias identitárias; reclama-se, assim, a necessidade de abandonar uma visão solipsista branca, essencialista e redutora que conceptualiza o género como a única forma de subordinação das mulheres (C. Nogueira 2011) e também o regresso a um feminismo ideologicamente radical, ou seja coerentemente antipatriarcal, anticapitalista e antisexista; nas palavras da autora «as políticas feministas estão a perder terreno porque o movimento feminista perdeu definições claras. Nós temos essas definições. Vamos retomá-las. Vamos compartilhá-las. Vamos começar de novo» (hooks 2000: 6). Como lembra Sandra Harding (2004: 8), o feminismo tem uma longa história de associação a movimentos liberais e outros, «luxos burgueses» muitas vezes discriminatórios, racial e etnicamente. O objetivo destas alianças seria atingir um público mais alargado, tornando-se assim mais eficaz, mas este caminho não passou nunca de um engodo por deixar à margem do feminismo justamente as mulheres mais oprimidas. 
Pese embora os trabalhos anteriores (e.g. hooks 1982/1990; Davis 1982), é Kimberlé Crenshaw (1991) quem, durante a década de 1980, cunha o termo Intersecionalidade, conceptualizando-o como a teoria que procura compreender as consequências da profusão de afiliações presentes nas mulheres, mostrando que a interação destas várias categorias, social e culturalmente construídas, podem potenciar desigualdades sociais e discriminações (e.g. C. Nogueira 2011). Contudo, se inicialmente esta teorização assumia a pertença a um grupo social como suficiente para constituir a base de uma ação política, esquecendo diferentes possibilidades de posicionamento ideológico dentro de um mesmo grupo de mulheres, o trabalho de Patricia Hill Collins, durante a década de 1990, aborda as múltiplas e simultâneas pertenças enquanto «matriz de dominação». A partir deste momento, a teoria da Intersecionalidade incorpora uma perspetiva construtivista social, que parte da ideia de que o conhecimento é socialmente construído, sendo por isso parcial. Assim, no lugar das metanarrativas, assume-se uma pluralidade e diversidade de posições e narrativas localizadas para dar voz às múltiplas realidades que surgem a partir das experiências vividas (Collins 2000), com particular destaque para a família e as formas de conhecimento não académicas.

A teoria da Intersecionalidade surge no seio da Psicologia Social Crítica e da teorização feminista de terceira vaga e faz parte de uma abordagem diversificada e polifónica que Harding agrupará sob a designação Standpoint Theory (2004). Como refere João Oliveira, «deixa de querer habitar apenas nesse espaço da «mulher» e passa a querer entender as imbricações das várias multitudes contidas nessas mulheres» (2010, 30). À perspetiva de um ponto de vista situado, próprio da experiência de cada sujeito, junta-se a ideia de um ponto de vista que resulta das conjunções das relações de poder de sexo, de raça, de classe, o que torna ainda mais complexa, mas extremamente pertinente, a própria noção de «conhecimento situado».

\section{Pensar sobre cinema}

Este texto não pretende ser uma análise exaustiva das representações das mulheres no cinema moçambicano, mas insere-se numa investigação doutoral que procura compreender as representações identitárias na ficção cinematográfica de lente pós-colonial portuguesa e moçambicana. Sem querer adentrar nas questões relativas às fronteiras entre documentário e ficção, entende-se aqui por ficção os filmes que são assumidos pelos seus autores como tal. Acresce-se que as entrevistas a autores utilizadas foram feitas no âmbito da investigação doutoral em curso. Não podendo alongar a exposição sobre a expressão «lente pós-colonial», clarifica-se apenas que neste contexto se refere a um conjunto de filmes que refletem as complexas relações e consequências, nem sempre evidentes, do colonialismo (enquanto sistema político, económico e social assumido) nas sociedades contemporâneas (Tazzioli e Belcher 2015) que pelo menos do ponto de vista institucional já não são coloniais. 
Ainda que se considere importante colocar em diálogo os filmes analisados com as tradições de cinema, uma vez que é sobre cinema a reflexão aqui proposta, esta é uma análise iminentemente política e social. A escolha da Intersecionalidade - uma teoria de análise crítica feminista, que visa a análise da opressão - pressupõe a compreensão dos objetos analisados enquanto participantes de sistemas de opressão. Primeira dificuldade: os filmes contam histórias de opressão; os filmes são veículos de opressão, no sentido em que reificam representações opressivas; ou os filmes são em si mesmos produtos de opressão, isto é: produtos que reproduzem opressão no processo da sua construção/produção? Ou tudo isto?

Para fazer uma aproximação crítica ao cinema moçambicano através da teoria da intersecionalidade, pode começar-se pela rotina de perguntas sugerida por Kimberlé Crenshaw:

Onde está o sexismo nisso? Qual a sua dimensão de classe? Onde está o heterossexismo? [...] De que forma esse problema é matizado pelo regionalismo? Pelas consequências históricas do colonialismo? $(2002,183)$.

Estas perguntas serão colocadas aos filmes que constituem o corpo fílmico aqui analisado, embora nem sempre pela mesma ordem e com matizes que decorrem das especificidades de cada obra e do contexto em que nasceu. Há, no entanto, outras questões além das de género e de classe envolvidas nesta abordagem e um novo conjunto de perguntas se impõe para conseguir maior profundidade da análise:

Há racismo atuando na determinação de quais mulheres serão sujeitas a tais condições de trabalho? Há alguma outra estrutura de poder que permite que essas condições continuem? Na arena global mais ampla, o que contribui para a existência dessas condições? (Crenshaw 2002, 183).

Moçambique é um país onde apenas uma minoria ínfima da população é branca, logo as questões de raça não podem ser formuladas do mesmo modo. No entanto, as perguntas são pertinentes se estendermos a análise aos lugares da produção. O projeto intelectual (por vezes negligenciado) da intersecionalidade exige que pensemos em indivíduos, povos e sistemas como se fossem hologramas - o que significa que não podem ser decompostos na sua «faceta étnica» versus a sua «faceta de género» versus a sua «faceta de classe» (Hancock 2012). Uma análise integrada de todas as partes do «holograma» torna-se particularmente complexa e resulta, na maioria das vezes, em humildes tentativas ou aproximações.

\section{Uma aproximação intersecional ao cinema moçambicano}

Em Moçambique, nos primeiros quinze anos de independência, o cinema ocupa um lugar privilegiado na política do regime marxista-leninista da Fre- 
limo. ${ }^{2}$ «Nos anos 1975-1991, o Instituto Nacional de Cinema (INC) irá dominar o mundo do cinema em Moçambique em todas as áreas desde a produção e distribuição até exibição de filmes» (Convents 2011, 364). O impacto da política do Estado sobre a programação de filmes na cidade e no campo foi grande, o «Estado procura uma política cinematográfica adequada para construir um «novo mundo»» (Convents 2011, 10). A perspetiva moçambicana sobre o colonizador é nesta altura fonte de inspiração para o cinema:

Ideologicamente e tematicamente concebido no espírito da luta de libertação contra o português no final dos anos setenta, os filmes dos países lusófonos, especialmente Moçambique e Angola, são um capítulo importante na história do cinema de África em geral e da história do cinema «guerrilha» ou de liberação, em particular (Watkins 1995, 110).

O cinema está sob tutela do Ministério da Informação, é controlado pelo secretariado do Departamento de Informação e Propaganda (DIP) e cria-se um circuito nacional de distribuição de filmes, controlado e dirigido pela Frelimo, dedicado à divulgação de filmes produzidos e realizados pelo DIP e outros filmes (russos, italianos, etc.) com a mesma orientação política.

Embora raramente articulada na forma de textos teóricos, a experiência de cinema em Moçambique nesta altura gera novos conceitos, estéticas e estratégias (Gray 2012). À tradição cineclubística anterior à independência junta-se agora a vontade de formar técnicos capazes de fazer um cinema ao serviço do povo moçambicano e livre dos «vícios» do colonialismo e do imperialismo: «de certa maneira nessa altura a visão era ter esses meios audiovisuais como um veículo para transmitir mensagens que fossem do interesse do próprio poder do dia» (entrevista a Gabriel Mondlane). ${ }^{3}$ Os acontecimentos políticos e culturais da época em Moçambique entusiasmam intelectuais e artistas de outros países e a jovem república estabelece protocolos de formação com países como o Brasil, Cuba e França (Convents 2011; Watkins 1995).

Nas palavras de Gabriel Mondlane:

Nós fazíamos seminários quase todas as semanas. Víamos os filmes e discutíamos com diferentes realizadores, diferentes filmes. Recebíamos gente conhecedora dessa área do cinema que viessem, tínhamos sempre uma palestra. Isso foi muito bom para a criação de mentalidade cinematográfica. Foi muito bom para nós. Então nós estávamos aqui com chilenos, com franceses, com ingleses, com cubanos, estávamos com

Frelimo, o partido que assumiu o governo depois da independência do país, nasceu da Frelimo (Frente de Libertação de Moçambique), que foi oficialmente fundada em 25 de junho de 1962 como movimento nacionalista, e tinha o objetivo de lutar pela independência de Moçambique do domínio colonial português. O primeiro presidente do partido foi o antropólogo Eduardo Chivambo Mondlane (Jafar 2014).

3 Entrevista a Gabriel Mondlane, cineasta e diretor da Amocine (associação de cineastas moçambicanos) , realizada pela autora em abril de 2016, em Maputo. 
brasileiros... então era muita nação aqui junta, muita nação aqui junta... (entrevista a Gabriel Mondlane).

A Frelimo nesta altura apoia os movimentos de libertação da Rodésia e a luta contra o apartheid na África do Sul, o que se traduziu em termos internos numa guerra civil ${ }^{4}$ que devastou o país e teve consequências nos temas abordados pelo cinema, como explica Licinio Azevedo: «o nosso programa, que tinha um cariz educativo no começo, começou a abordar a situação social no país de uma maneira mais ampla, fazendo documentários sobre a guerra» (Pereira e Cabecinhas 2015, 1033). No entanto, «com o passar dos anos, a Rodésia deu lugar ao Zimbabwe, cujas forças lutavam agora do lado da Frelimo. O brutal envolvimento das forças do país vizinho, contudo, em nada mudou a direção da guerra» (Cabral 2005, 236). A guerra e a degradação das condições económicas no país dificultaram a produção e a importação de filmes, permitiram (por falta de investimento) a deterioração das salas de cinema e conduziram a que durante a década de 1980 a qualidade e a quantidade do cinema que se podia ver em Moçambique tivesse piorado substancialmente. No início da década de 1990, o vídeo ocupa o lugar que o cinema deixara vago.

Na década de 1990, quando a República Popular de Moçambique passa a ser apenas República de Moçambique, os meios de comunicação social, e com eles o cinema, são liberalizados. Os cineastas oriundos do INC e da Kanemo ${ }^{5}$ estão na base da formação das empresas que serão a espinha dorsal da «revolução» que se avizinha e são ainda hoje, como se irá ver, através dessas empresas, protagonistas do cinema moçambicano. $\mathrm{O}$ acesso às novas tecnologias digitais facilitou o aparecimento de novas oportunidades para uma cultura da imagem que desde a independência do país se «escora no cinema e alimenta-se no documentário» (Convents 2011, 642). No entanto, a degradação que a guerra tinha provocado, e sobretudo o abandono de políticas protecionistas do cinema, conduziram o cinema moçambicano a uma crise profunda, como revela o realizador Licinio Azevedo:

É uma tristeza, principalmente porque não há formação. A Amocine ou outras organizações fazem pequenos cursos de uma semana ou duas. Uma escola de cinema são

4 Guerra civil, ou conflito armado, que opunha a Renamo e as forças do governo da Frelimo. A Renamo, acrónimo de Resistência Nacional Moçambicana, é hoje o 2. ${ }^{\circ}$ maior partido moçambicano, liderado por Afonso Dhlakama. Foi fundada em 1975, após a independência de Moçambique, como uma organização política anticomunista. Era patrocinada pela Organização Central de Inteligência da Rodésia (hoje Zimbabwe). Ian Smith, primeiro-ministro da Rodésia, procurava por meio da Renamo impedir que o governo da Frelimo fornecesse refúgio para a União Nacional Africana do Zimbabwe, organização que pretendia derrubar o governo da Rodésia, o que veio a acontecer em abril de 1980 (Jafar 2014).

5 A Kanemo foi uma produtora criada oficialmente em 1983 para suprir as necessidades de produção cinematográfica do país, uma vez que o INC não conseguia responder a todas as demandas (T. Nogueira 1986). 
4 ou 5 anos, não é? E você precisa ter uma preparação prévia: para fazer cinema você precisa conhecer arte, história, literatura, tudo isso... e para já essa base não existe nas novas gerações, depois não há escola de cinema. Então, os jovens que fazem cinema, são jovens que saíram de pequenos cursos, que gostam de cinema e acham que é uma coisa leve e fácil... eu acho que o grande problema é que a nossa geração, que é a geração de resistência ainda, somos os últimos (Pereira \& Cabecinhas 2015, 1035).

E assim sendo, grande parte dos cineastas no ativo são ainda os herdeiros de uma elite cultural colonial, quase sempre branca e predominantemente masculina. $\mathrm{O}$ «cinema mundo» produzido em Moçambique - rótulo que é atribuído pelos centros decisórios, ou seja, o norte do continente americano e a Europa - encontra-se hoje dependente dos circuitos internacionais de financiamento e do conceito de coprodução.

Como conclui João Ribeiro:

Infelizmente em Moçambique, e dentro do nosso horizonte, não há formas de financiamento, não há formas de produção, não há formas de exibição que não sejam essas de ir buscar dinheiro lá fora e de estar dependente dessas agendas, das agendas de quem dá. De quem dá o dinheiro; portanto que tipo de filme é que estão à procura de ver na tela, que tipo de países é que vão apoiar, isso também faz parte do processo de decisão... porque se apoiaram muitos filmes de Moçambique o ano passado, não vão apoiar mais este ano. Quer dizer há todo um conjunto de coisas... não é só um projeto bom. Teoricamente é: passa o melhor projeto, mas o júri é constituído por muitas pessoas, essas pessoas, cada uma dessas pessoas, tem a sua agenda, tem o seu objetivo e essas dependências existem (entrevista a João Ribeiro). ${ }^{6}$

Deste modo, torna-se hoje mais difícil estabelecer em Moçambique um centro de produção cinematográfico com a importância e a independência que teve na década de 1970 e que afirmava, inclusivamente, uma perceção diferente da história, do mundo e da arte: «Essas perceções divergentes entre os europeus, por um lado, e africanos, por outro lado, também destacaram a luta, mais ampla, da autonomia indígena pós-colonial africana, cultural e política contra o controlo económico e neocolonial» (Watkins 1995, 116).

No século XXI, o cinema em Moçambique permanece comprometido com as questões sociais e políticas, até pela continuidade do grupo autoral que o informa, mas doravante será necessário (re)questionar os limites do dizível e as lógicas de inclusão e exclusão (Foucault 1997 [1971]) a ele subjacentes. Vejamos: o género no cinema moçambicano aparece binário, prevalecendo a ideia de que a natureza o determina, além disso, nos filmes de ficção moçambicanos, são excluídos por supressão (van Leeuwen 2008) várias minorias, por exemplo gays, lésbicas, trans, indianos, portugueses, albinos e deficientes (estes últimos não aprecem representados, mesmo

Entrevista a João Ribeiro, cineasta, realizada pela autora em abril de 2016, em Maputo. 
em filmes de guerra ou do pós-guerra). A explicação primeira para esta realidade surge demasiado óbvia para se poder confiar nela: o cinema é feito por homens, quase sempre brancos, intelectualmente europeus/ocidentais, percecionados como heterossexuais e de classe média/alta. Trata-se, no entanto, maioritariamente de uma classe profissional filiada numa tradição filosófica, política e artística de esquerda, profundamente anticolonialista e com preocupações políticas e sociais expressas. A intenção de representar um sujeito subalternizado, que não pode ocupar uma categoria monolítica uma vez que esse sujeito é heterogéneo, deveria ter em conta a possibilidade da sua própria voz fazer parte do discurso, como sugere Spivak (2010 [1985]), caso contrário serão sempre outros (intelectuais, artistas, etc.) a falar por ele e todo o intelectual está já desinvestido da possibilidade de dar voz ao subalterno.

\section{O Jardim do Outro Homem}

Nascido em 1953, em Moçambique, Sol de Carvalho cresceu em Inhambane. Estudou cinema em Portugal entre 1972 e 1974. Na sequência do 25 de Abril, regressou a Moçambique para se juntar ao projeto independentista da Frelimo. Depois da independência do país, foi destacado como chefe do Serviço Nacional da Rádio Moçambique, onde permaneceu até ser transferido para a revista Tempo, em 1979. Em 1984, fez, como 3. ${ }^{\circ}$ assistente, a primeira longa-metragem moçambicana, coproduzida por Moçambique e pela Jugoslávia, ${ }^{7}$ e, depois, 56 edições do jornal cinematográfico Kuxa Kanema. ${ }^{8}$ Foi sócio-fundador da produtora Ébano (juntamente com Pedro Pimenta e Licinio Azevedo), da qual se desligou posteriormente para fundar a Promarte.

\section{Figura 1}

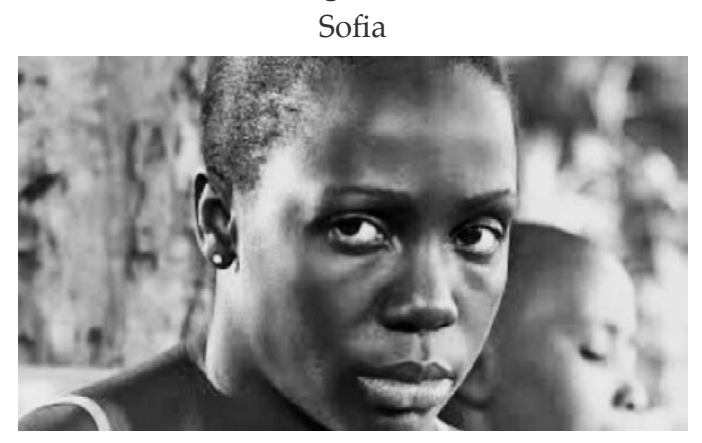

(C) Sol de Carvalho

O Tempo dos Leopardos (1984), de Zdravko Velimorovic.

Kuxa Kanema (nascimento do cinema) foi um jornal cinematográfico semanal moçambicano, produzido pelo INC, entre 1976 e 1986, cujo lema era «filmar a imagem do povo e devolve-la ao povo», e foi um elemento-chave na reificação do regime de Samora Machel e de apoio à construção de uma identidade nacional. 
O Jardim do Outro Homem (2006), de Sol de Carvalho, foi a primeira longa-metragem (80 minutos) de ficção do cinema moçambicano em 20 anos, sendo a terceira até então, ${ }^{9}$ e foi coproduzida por Portugal, França, União Europeia, Suíça, Suécia e Moçambique. O filme foi financiado com objetivos claros de informar sobre e prevenir o flagelo do VIH. Em entrevista a Policarpo Mapengo (2010), Sol de Carvalho exprime o seu ponto de vista sobre as dinâmicas de produção da obra:

quando fazemos um filme sobre HIV/SIDA, a primeira coisa que temos de fazer é um filme. As pessoas dizem que já que têm lá a mensagem sobre SIDA, está bom. Mas não está! As tendências dos doadores são as de que tem que se fazer o filme politicamente correto, mas, por vezes, o politicamente correto não é um bom filme. Já conseguimos convencer os doadores que o dinheiro, além de apoiar as campanhas sociais, permite falar de desenganos, de amor e das tradições. Convencê-los que pôr dinheiro no orçamento do Estado, na balança de pagamentos, no Ministério das Finanças e no Ministério da Educação não chega, porque se não resolve o problema da cultura, não resolve o problema do país (Mapengo, 2010).

Em O Jardim do Outro Homem, as questões de género, raça e classe na sociedade moçambicana aparecem de forma explícita e são centrais. A ação decorre em Maputo, na primeira década do século XXI. São representadas várias gerações de mulheres, de diferentes classes sociais, sendo que a opressão que as mulheres sofrem tem origens diversas e manifesta-se de forma diferente consoante determinam essas mesmas origens de opressão. Os homens também são, com frequência, vítimas do poder porque são assalariados (mal pagos) do Estado, mas reproduzem o esquema com os ainda mais desafortunados: as mulheres. Ainda que o filme fale de uma realidade em que as mulheres são entendidas como objetos sexuais, as mulheres de O Jardim do Outro Homem não são representadas como objetos sexuais. Os raros momentos em que o filme se torna contemplativo são sequências como a de um lenço que voa sobre um vale, ou quando Jéssica (Amélia Muate) desfila em bikini - a câmara afasta-se para se colocar no lugar do homem que a observa, mas paradoxalmente cria-se assim um distanciamento. Deste modo, apesar de se tratar de um filme comercial, e portanto feito para chegar ao maior número de pessoas possível, não segue as lógicas patriarcais de representação da mulher apontadas, por exemplo, por Laura Mulvey (1999) ao cinema ocidental mainstream.

O filme Mueda, memória e massacre (1979/80), de Ruy Guerra, embora tenha sido promovido como ficcional e seja por vezes assim considerado (Schefer 2016) não é aqui referido como tal, na medida em que que este filme pode ser classificado como: reconstituição; documentário político; ficção histórica; filme etnográfico, talvez entre outros, afastando-se assim da designação genérica «ficção», quer em termos de produção, quer formais. Restam assim, além do referido O Tempo dos Leopardos (1984), também O Vento Sopra do Norte (1987), de José Cardoso, este último considerado a primeira longa-metragem inteiramente moçambicana. 
A tensão dramática explicita-se no primeiro momento: Sofia (Gigliola Zacara) sonha que é médica. O irmão pequeno chora, ao mesmo tempo que uma barata percorre o colo da jovem. A presença do inseto anuncia o ambiente em que a personagem se insere socialmente: a casa da família está localizada na periferia de Maputo onde convivem lado a lado lixo depositado ao ar livre e produtos alimentares que se vendem na rua; onde os acessos são difíceis e não existem infraestruturas; onde residem os moçambicanos pobres do pós-guerra, ${ }^{10} \mathrm{em}$ barracos pequenos e sem luz elétrica. A câmara de Carvalho segue Sofia desde o seu sonho interrompido pela realidade, de madrugada, em casa, distante da escola, até à «outra» cidade, a que tem que ser conquistada, que está distante de Sofia, e que só se vê através dos vidros embaciados do transporte coletivo. ${ }^{11}$

Maputo é retratada como espaço onde se confrontam diversos mundos: o mundo tradicional da cultura milenar, representado pela avó de Sofia, conhecedora dos costumes e remédios ancestrais, e o mundo moderno que coloca problemas que os saberes tradicionais não resolvem. Como dirá Sofia, «É preciso saber, é preciso saber», mostrando claramente que, para ela, a sabedoria tradicional não é suficiente, é preciso dominar o conhecimento científico. Valores de um mundo contraditório, patriarcal, poligâmico e de assédio sexual, onde os homens sentem a necessidade de usar preservativo nas relações sexuais como uma afronta. E por isso talvez não seja de estranhar que, neste mundo, as mulheres só contem com a solidariedade umas das outras. Sofia só encontra apoio noutras mulheres; primeiro as da família, pois estas, mesmo pobres e provavelmente analfabetas, sustentam-na e vão-lhe pagando os estudos - curiosamente a avó é a sua principal aliada. Fora de casa, ela encontra apoio também em mulheres; a médica, que pode ser lida como um espelho de Sofia, pois, como ela, foi assediada e lutou para entrar na faculdade de medicina; Jéssica, a sua amiga e companheira de infortúnio e a professora estrangeira.

A família de Sofia é inteiramente constituída por mulheres, porque o pai emigrou para a África do Sul, onde constituiu uma nova família e nunca mais voltou. Sobrevivem trabalhando numa pedreira. Para alcançar o sonho de ser médica, Sofia vai ter que lutar contra os preconceitos da sociedade que estão presentes na sua própria família: pagar os estudos a uma jovem mulher é plantar o jardim de outro homem, porque depois de formada ela vai trabalhar e ganhar dinheiro não para a família de origem, mas para a do marido. Além disso, o namorado que sonha ser futebolista e jogar em Portugal acha que Sofia está a perder tempo na escola, porque ele vai ganhar muito dinheiro e nessa altura ela não terá que trabalhar. Finalmente e pior de tudo, Sofia tem que lidar com a chantagem do Professor

10 Durante a guerra civil referida no ponto anterior deste trabalho, muitos moçambicanos originários das zonas rurais refugiaram-se na periferia da capital do país Maputo - onde a guerra não chegou e onde vivem até hoje.

${ }_{11}$ Chapa: carrinhas de nove lugares habitualmente usadas como transporte coletivo em Maputo. 
Mangueira (Evaristo Abreu) que só a passa de ano em troca de favores sexuais. Em O Jardim do Outro Homem as dificuldades de Sofia aparecem associadas aos valores das comunidades tradicionais moçambicanas.

O filme apresenta também uma realidade em que os professores da escola pública não auferem ordenados que lhes permitam viver condignamente. Estes funcionários exploram os alunos obrigando-os a «pagar» as passagens de ano, e abusam das alunas obrigando-as a fazer sexo com eles. No início do filme, é noticiada a morte de um professor vítima de «doença prolongada» e os alunos percebem que ele tinha contraído o vírus da SIDA. Como consequência, Jéssica fica com medo de estar contaminada, uma vez que já tinha sido abusada sexualmente por esse professor. Jéssica sofre também de abuso por parte de um estrangeiro branco que - talvez por acreditar que poderá disfrutar de prazeres exóticos impossíveis de obter na sua terra (Said 2013 [1978]) - lhe promete um contrato de trabalho como modelo, em troca de sexo.

Os «brancos» são apresentados no filme como um grupo à parte dos moçambicanos como Sofia e os seus amigos. Não há comunicação. Uma professora branca (cooperante) tenta aproximar-se, mas está muito condicionada por todo o contexto; Sofia diz-lhe «a Senhora Professora está aqui este ano, mas para o próximo ano já não estará». E há também homens brancos representados pelo empresário de moda abusador e pelo caçador de impalas; nos momentos de maior tensão, há uma alternância de planos para mostrar cenas de uma impala, sempre atenta aos predadores. A escolha da impala para dialogar com a tensão dramática vivida pela personagem principal sublinha a necessidade de Sofia de estar com os sentidos alerta e preparada para lutar e despistar os seus predadores: a pobreza, a saudade do pai ausente, o assédio do professor, o machismo do namorado e o VIH. A impala é também símbolo de Moçambique, de modo que há uma relação metafórica entre a personagem, o animal e a nação, que precisa, como a impala e como Sofia, de se livrar dos seus predadores. A progressão da história, com pouquíssimas digressões e alguns momentos subjetivos, vai «encurralando» a protagonista e também a impala, obrigando-as a reagir.

\section{Virgem Margarida}

Nascido em Porto Alegre, no Brasil, em 1951, Licinio Azevedo vive em Moçambique desde a segunda metade da década de 1970, onde criou uma cinematografia constituída por alguns filmes de ficção, mas fortemente ancorada no documentário, um pouco à semelhança, nesse aspeto, do cinema moçambicano em geral (Convents 2011). Foi jornalista de formação e profissão até à sua chegada ao INC, a convite de Ruy Guerra, onde começou a fazer cinema. A guerra, que assolou o país entre 1977 e 1992, acabou por se transformar na «personagem» central dos seus filmes. Na década de 1990, Azevedo fundou a Ébano Multimédia (juntamente com Pedro Pimenta e Sol de Carvalho).Virgem Margarida (2012) é a primeira 
longa-metragem (90 minutos) de ficção do autor mais premiado e reconhecido internacionalmente do cinema feito em Moçambique e precede $O$ Comboio de Sal e Açúcar que teve a sua estreia em 2016.

Virgem Margarida conta a história de um grupo de prostitutas que foi levado para um campo de reeducação socialista depois da independência de Moçambique. O filme é baseado no documentário A Ultima Prostituta (1999), que o autor tinha feito sobre o mesmo tema e foi coproduzido por Portugal, França e Moçambique:

Quando eu fiz A Última Prostituta, que deu origem à Virgem Margarida, era um filme que era um tema tabu, não é? Eu tinha feito esse filme há 10 anos, era tabu porque era sobre esse processo de reeducação que foi muito violento. Muitas mulheres morreram nos centros de reeducação... pode chamar de centros de concentração se você quiser... uma maneira doce de dizer campos de concentração é centros de reeducação... porque era suposto saírem dali mulheres novas, não é? Para serem mães de família e tal, não é? Queriam salvar... aquela coisa quase cristã de recuperar as prostitutas. Transformar em mulheres úteis à revolução e tal, ao socialismo vigente na época... (Pereira e Cabecinhas 2015, 1034).

Em Virgem Margarida são colocadas em evidência algumas questões relativas aos regionalismos, em Moçambique, pela presença de personagens de etnias (culturas) diferentes e através da representação das dificuldades de relacionamento entre estas. A união nacional, a identidade moçambicana, hoje chamada moçambicanidade, foi construída depois da independência e muito através do cinema, mas não só. Este filme mostra a construção dessa unidade nos chamados campos de reeducação através do exército. O país que é muito vasto e diversificado, é constituído por vários povos com línguas e culturas diferentes, que, em muitos casos, não tinham qualquer conhecimento mútuo e a quem foi preciso transmitir uma ideia de unidade. Virgem Margarida revela um aspeto dessa construção de unidade nacional, precisamente a dos campos de reeducação para mulheres, que se configura na opressão generalizada de todas as mulheres, na humilhação das práticas culturais consideradas menos urbanas (obscurantismo, o regionalismo e o tribalismo) e na uniformização dos usos e costumes. Diz a camarada comandante Maria João (Ermelinda Cimela): «Vocês aqui são do sul. As demais são do centro do país. Todas possuem mentes colonizadas. Devem aprender que são mulheres da mesma pátria. Vão aprender a comportar-se como mulheres novas.» 
Figura 2

Castigo corporal e psicológico no «campo de reeducação»

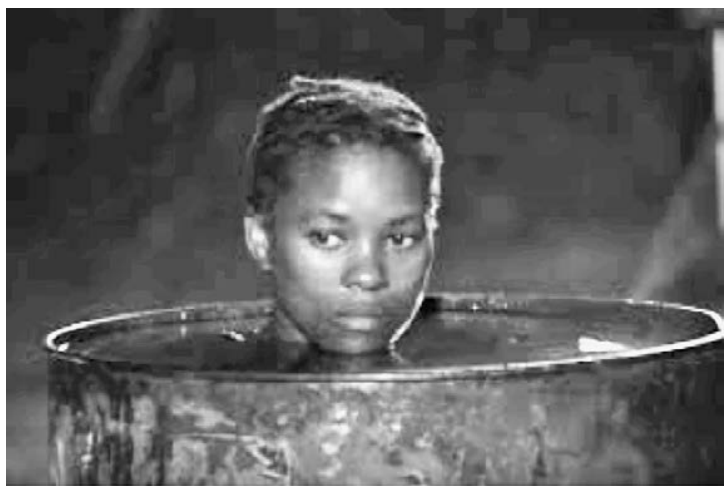

(C) Licinio Azevedo

É preciso realçar que as mulheres não estão a ser ensinadas a ler, a escrever ou a pensar mas, sim, a fazer machambas (pequenas hortas), a cozinhar, lavar, etc. para serem boas esposas e mães e dessa forma úteis à construção da nova sociedade. A revolução tem princípios claros e universais que são mais difíceis de atingir (e praticamente incompreensíveis) para umas mulheres do que para outras. Se além de ser mulher, pobre e prostituta, for culturalmente ligada a tradições consideradas antirrevolucionárias, ou simplesmente atávicas, a opressão fazer-se-á sentir de forma ainda mais intensa, tanto mais que não poderá contar com a solidariedade das outras mulheres. Ainda que seja uma história em que as mulheres acabam por se unir contra a dominação patriarcal, é bem visível a reprodução de pensamento sexista. A ordem burguesa instalou um sistema que exclui através da sexualidade - os direitos das mulheres e das crianças estão dependentes dos seus contratos conjugais com os homens. A família fornece as fundações naturais da vida civil e a maternidade é entendida como um «serviço nacional», sendo que a ela se restringem os direitos das mulheres (Stoler 1995). Deste modo, assistimos em Virgem Margarida à imposição de uma ordem social moralmente burguesa, ainda que a filiação político-partidária que a instiga seja marxista.

Existem também, além de várias etnias, diversos grupos sociais entre estas mulheres. Se observarmos as personagens principais, percebemos que são, de alguma forma, emblemas de uma sociedade e de uma época: Margarida (Sumeia Maculuva), a camponesa virgem, adolescente, lobolada (noiva) e analfabeta que representa o povo mais humilde, arreigado a tradições ancestrais, profundamente conhecedor do trabalho na terra, da natureza e dos seus perigos; Susana (Rosa Mário), sonhadora, pequeno-burguesa, mãe de duas crianças, que recusa a sua condição de mulher objeto, assumindo-se como bailarina e que sucumbe às provações da experiência «educativa»; Rosa (Iva Mugalela), a prostituta livre que se transforma em líder do pequeno grupo, é talvez a mais literária das personagens 
de Azevedo, uma heroína revolucionária que acaba por ajudar o grupo a manter-se unido e finalmente a libertar-se; e, por último, a camarada comandante Maria João, a opressora oprimida - os membros femininos do exército são simultaneamente oprimidos e agentes de opressão. $\mathrm{O}$ verdadeiro poder é inteiramente masculino e o abuso também: depois de ter combatido dez anos, a camarada comandante Maria João é obrigada a protelar o seu casamento, o seu plano de constituir uma família, para reeducar prostitutas e transformá-las, a fim de torná-las mulheres úteis ao Moçambique novo.

É curioso observar que num filme onde quase todas as personagens são mulheres prostitutas não existem cenas de sexo, nem sequer de particular sensualidade. A única cena em que aparecem mulheres seminuas que tomam banho num rio, é de uma singeleza infantil e não erótica. Segundo Dulucq, no cinema subsariano «A mulher enquanto objeto sexual e as suas variações infinitas («mulher fatal», «mulher-criança», «mulher-objeto», «galdéria», «vamp», etc.) é pouco representada, ainda que seja uma figura central no cinema ocidental» (Dulucq 1997, 19). As heroínas do cinema moçambicano e dos filmes de Azevedo seguem aparentemente a mesma tradição. Ao contrário do que algumas leituras clássicas do cinema ocidental revelam (e. g. Mulvey 1999), em Virgem Margarida a lógica narrativa não segue a lógica heteronormativa (ativo/passivo) da divisão do trabalho. Não é dada a personagens masculinas a condução da ação, nem a possibilidade, por parte do público, de identificação com este tipo de herói; o homem aparece em Virgem Margarida, sim, mas como pano de fundo, ele é o próprio Sistema que as oprime e que delas abusa, mas contra o qual se vão impondo. Assim, a ação e o protagonismo é dado às mulheres, embora o Sistema representado pelo Camarada Comandante e que o filme denuncia seja patriarcal.

A camarada comandante Maria João defende (a par com o regime) que a vida que as mulheres levavam antes de serem enclausuradas no campo de reeducação era fruto dos «vícios do capitalismo» e vê todas as dificuldades de aceitação das novas regras como reflexo das «mentes sujas» do colonialismo. Por esse motivo é particularmente forte no filme o momento em que Rosa diz a Maria João «o camarada foi pior que o colono». Virgem Margarida revela o fracasso da mente colonizada em se emancipar - o poder político rejeita categoricamente toda a herança colonial portuguesa, mas, talvez sem se aperceber, segue códigos de conduta moral burgueses e «importa», ainda que noutras latitudes, estratégias políticas, novos modelos, que são também estranhos à cultura moçambicana e que a ela dificilmente se adaptam. Mais do que a substituição de um modelo de opressão por outro, o que vemos em Virgem Margarida é a reformulação do modelo de opressão patriarcal, em que as principais vítimas continuam a ser as mulheres. A opressão escala quando além de serem mulheres são pobres, pouco instruídas (ou mesmo analfabetas) e pertencentes a minorias étnicas. 


\section{Mulheres na ficção cinematográfica moçambicana do século XXI}

As personagens femininas de O jardim do Outro Homem e de Virgem Margarida afastam-se das representações de mulheres do cinema mainstream ocidental que «ordenadamente combinam espetáculo e narrativa» (Mulvey 1999) numa lógica patriarcal relativamente ao papel e à função da mulher e, por outro lado, seguem uma tradição das representações do feminino de filmes africanos. São heroínas simples das aldeias, ou das periferias das grandes cidades, como a empregada doméstica de Black Girl (1966), as meninas que fogem do rito de iniciação em Moolaadeé (2004), ambos de Ousmane Sembène, ou a cantora Vita, de Nhá Fala (2002), de Flora Gomes. São heroínas como as mulheres dos romances de Paulina Chiziane, que simbolizam o sonho de um Moçambique novo, mas também as principais vítimas dos períodos pós-coloniais, como Diminga de Mortu Nega (1988), de Flora Gomes. Dito de outro modo, estes filmes seguem uma já relativamente longa tradição do discurso cinematográfico africano sobre África, sobre a mulher africana, sobre a luta contra o (neo)colonialismo e contra o patriarcado inscrevendo-se, portanto, numa tradição africana de cinema. Assim, questionam algumas representações, mas reificam outras.

Sofia é uma adolescente que questiona a cultura patriarcal machista; primeiro, ousa sonhar ser médica; depois, desafia a tradição das mulheres da família, que ocupavam sem questionar o lugar da submissão. Sofia vai ainda mais longe, abandona o namorado, em vez de perdoá-lo pelo adultério e decide continuar os estudos. É na rutura com o machismo e com a cultura que o sustenta que a trama se desenvolve. Sofia reage e não permite a consumação do ato sexual com o professor sem o uso de preservativo. Ele torna-se agressivo, mas ela foge, no momento em que chega socorro, por via da avó e das amigas. No plano seguinte, surge a imagem da impala, escapando de um tiro do caçador; no diálogo entre estes dois planos, o filme transmite esperança de um novo Moçambique e de uma nova mulher, que quebra correntes milenares.

Margarida é também uma adolescente, mas não tem qualquer desejo revolucionário, nem sonhos de uma vida diferente daquela para a qual foi educada. Morrerá no fim do drama e o seu suicídio simboliza, de alguma forma, o fim de um modo tradicional de vida para o qual não haverá espaço no Moçambique novo. Paradoxalmente, a personagem que é talvez a única intocada «pelas mentes sujas do colonialismo» não tem lugar num mundo que se quer livre da referida mentalidade. As companheiras de desventura de Margarida, pelo contrário, salvam-se porque agem em grupo. O filme, que pode ser lido como uma crítica ao regime marxista-leninista do período pós-independência moçambicana, propõe curiosamente uma solução ainda marxista para a libertação das mulheres - é agindo como grupo/classe social oprimida por inimigos comuns (a ditadura, o patriarcado, o classismo, a corrupção) que as mulheres podem libertar-se. Azevedo parece ir ao encontro de um pensamento feminista intersecional: o corpus teórico que San- 
dra Harding (2004) nomeou Standpoint Theory revela que experiências diferentes podem originar conhecimentos diferentes, e que essa possibilidade foi sempre ignorada, porque ao longo da história do conhecimento os grupos dominantes tentaram mantê-lo de si para si. Mais, segundo esta autora, o empoderamento requer um tipo de conhecimento específico - ao serviço de projetos pessoais/subjetivos concretos - e essa forma de conhecimento só pode emergir através de processos políticos.

No ensaio Pode o Subalterno falar?, de 1985, Gayatri Spivak (2010 [1985]) sugere que toda a representação feita em nome de um subalterno poderá ser entendida como condescendência ou paternalismo e falhar nas reivindicações. Por outro lado, pergunta ainda a autora, será não dizer nada uma opção defensável eticamente? Ficar calado é assumir cumplicidade com as classes e os grupos sociais no poder, por isso o intelectual, e neste caso o artista, tem a responsabilidade de não se demitir da representação dos subalternizados. Talvez o cinema moçambicano (no caso concreto dos filmes analisados) represente uma forma de seguir a proposta de Spivak, que consiste em criar um espaço para o subalterno falar e, depois de criado esse espaço, ouvi-lo. Melhor dizendo: ouvi-la, porque para a autora o termo aplica-se sobretudo às mulheres pobres do «terceiro mundo»: duplamente silenciadas, duplamente na sombra.

As contingências de produção e a necessidade de ajuste dos temas tratados aos interesses das agendas internacionais condicionam certamente o cinema moçambicano na sua quantidade e diversidade. Ancorado numa tradição comprometida social e politicamente e pela sua natureza polissémica, o cinema moçambicano consegue trazer à discussão pública questões como sexismo, classismo, abuso de poder, etnicidade, aproximando-se, por vezes, da sugestão de abordagem aos problemas feita pela Teoria da Intersecionalidade. A mulher moçambicana debate-se com graves problemas, que se prendem com a frágil situação política e económica do país, tanto quanto com uma forte estrutura patriarcal socialmente inquestionada. No cinema feito em Moçambique, a Mulher aparece ao serviço de uma possibilidade de um país novo, e as suas reivindicações confundem-se com os sonhos daqueles que fazem cinema. Esta idealização da mulher «heroína revolucionária», que não deixa de ser excludente de todas as mulheres que não se enquadram neste arquétipo, está, apesar disso, ao serviço do combate a formas de opressão múltiplas e imbricadas e, portanto, é um instrumento de luta política. E é precisamente nesse sentido que se considera a intersecionalidade ao mesmo tempo um "projeto de conhecimento e uma política», que diz respeito "às condições sociais de produção de conhecimentos» e à questão da «justiça social» (Hirata 2014: 69). O cinema, melhor que outros meios, pode ajudar a suprir «a necessidade de pensar conjuntamente as dominações» (Kergoat 2012: 20) a fim de contribuir para a sua não reprodução. 


\section{Referências Bibliográficas}

Azevedo, Licinio. 2012. Virgem Margarida. Portugal, França, Moçambique, Angola. (Filme). Cabral, João de P. 2005. «Crises de Fraternidade: Literatura e Etnicidade». Horizontes Antropológicos, 229-253.

Carvalho, Sol. 2006. O Jardim do Outro Homem. Portugal, França, União Europeia, Suíça, Suécia, Moçambique. (Filme).

Collins, Patricia H. 2000. Black Feminist Thought. Knowledge, Consciousness, and the Politics of Empowerment. Londres: Routledge

Convents, Guido. 2011. Os moçambicanos perante o cinema e o audiovisual. Maputo: Dockanema.

Crenshaw, Kimberlé. 1991. «Mapping the Margins: Intersectionality, Identity, Politics and Violence against Women of Color». Stanford Law Review 43 (6): 1241-1299. Doi: https:// doi.org/10.2307/1229039

Crenshaw, Kimberlé. 2002. «Documento para o encontro de especialistas em aspectos da discriminação racial relativos ao gênero». Estudos Feministas 10 (1): 171-188. Doi: https://doi.org/10.1590/S0104-026X2002000100011

Davis, Angela. 1982. Women, Race and Class. Londres: The Women's Press.

Dulucq, Sophie. 1997. «'Visages de femmes' au miroir du cinéma d'Afrique noire (des années 1960 aux années 1990)». Clio. Histoire, femmes et sociétés 6. Doi: https://doi. org/10.4000/clio.380

Foucault, Michel. 1997 [1971]. A Ordem do Discurso. Lisboa: Relógio D’Água.

Gray, Ros. 2012. «Cinema on the cultural front: Film-making and the Mozambican revolution». Journal of African Cinemas 3 (2): 139-160. Doi: https://doi.org/10.1386/jac. 3.2.139_1

Hancock, Ange-Marie. 2012. «Empirical Intersectionality: Two Approaches». Irvine Law Review. University of California. 3 (259): 259-296.

Harding, Sandra. 2004. The Feminist Standpoint Theory Reader: Intellectual and Political Controversies. Londres: Routledge.

Hirata, Helena. 2014. «Gênero, classe e raça: Interseccionalidade e consubstancialidade das relações sociais.» Tempo Social, revista de sociologia da USP 26 (1): 61-73. Disponível no endereço http://www.revistas.usp.br/ts/article/view/84979

hooks, bell. 1990 [1982]. Ain't I a Woman. Black Women and Feminism. Londres: Pluto Press.

hooks, bell. 2000. Feminism is for Everybody. Passionate Politics. Cambridge: South End Press.

Jafar, Jafar Silvestre. 2014. «Análise Sócio-Histórica sobre a Guerra Civil em Moçambique 1976-1992: uma abordagem holística». ICS Working Papers. Montepuez: Universidade Pedagógica. Disponível no endereço http://www.ics.ul.pt/publicacoes/workingpapers/wp2014/wp2014_6.pdf [Consultado em abril 2017].

Kergoat, Danièle. 2012. Se battre, disent-elles... Paris: La Dispute.

Mapengo, Policarpo. 2010. «Uma história de desencanto - Entrevista com Sol de Carvalho.»O País. 27 de dezembro. Disponível em http://www.opais.co.mz/index.php/ entrevistas/76-entrevistas/11178-uma-historia-de-desencanto.html [Consultado em novembro 2016].

Mulvey, Laura. 1999. «Visual Pleasure and Narrative Cinema.» Em Film Theory and Criticism: Introductory Readings, editado por Leo Braudy e Marshall Cohen, 833-844. Nova Iorque: Oxford University Press.

Nogueira, Conceição. 2011. «Introdução à Teoria da Interseccionalidade nos Estudos de Género». Em Género e Ciências Sociais, organizado por Sofia Neves, 67-78. Maia: Edições ISMAI. 
Nogueira, Teresa S. 1986. «Cinema Moçambicano VII: Kanemo um Projecto de Cinema». Tempo 841: 44-45.

Oliveira, João M. 2010. «Os feminismos habitam espaços hifenizados - A Localização e interseccionalidade dos saberes feministas». ex aеquo 22: 25-39. Disponível no endereço http://www.scielo.mec.pt/pdf/aeq/n22/n22a05.pdf

Pereira, Ana C., e Cabecinhas, Rosa. 2016. «'Um país sem imagem é um país sem memória' - entrevista com Licinio de Azevedo». Estudos Ibero-Americanos, 42 (3): 1026-1047. Doi: https://doi.org/10.15448/1980-864X.2016.3.22989

Said, Edward. 2013 [1978]. Orientalismo. Lisboa: Livros Cotovia

Schefer, Raquel. 2016. «Mueda, Memória e Massacre, de Ruy Guerra, o projeto cinematográfico moçambicano e as formas culturais do Planalto de Mueda». Comunicação e Sociedade 29: 27-51. Doi: https://doi.org/10.17231/comsoc.29(2016).2408

Stoler, Ann L. 1995. Race and Education of Desire: Foucault's History of Sexuality and the Colonial Order of Things. Londres: Duke University Press.

Spivak, Gayatri C. 2010 [1985]. Pode o Subalterno Falar? São Paulo: Aufmg.

Tazzioli, Martina, e Belcher, Oliver. 2015. «Interview with Ann Laura Stoler». Darkmatter. 5 de dezembro. Disponível no endereço http://www.darkmatter101.org/site/2015/10/05/ interview-with-ann-laura-stoler [Consultado em abril 2017].

van Leeuwen, Theo. 2008. Discourse and Practice: New Tools for Critical Discourse Analysis. Nova Iorque: Oxford University Press. Doi: https://doi.org/10.1093/acprof:oso/ 9780195323306.001.0001

Watkins, Claire A. 1995. «Le cinema africain lusophone: perspectives historiques et contemporaines de 1969 à 1993». Ecran d'Afrique 13/14: 109-124.

Ana Cristina Pereira. Doutoranda em Estudos Culturais no Centro de Estudos de Comunicação e Sociedade da Universidade do Minho (CECS/UM); Mestre em Ciências da Educação pela Universidade de Aveiro; Licenciada em Teatro pelas escolas de Teatro e Cinema de Lisboa e de Música e Artes do Espetáculo do Porto. Com investigação sobre cinema, raça e género, é Bolseira FCT em regime misto.

Artigo recebido em 03 de janeiro de 2017 e aceite para publicação a 23 de fevereiro de 2017. 